Technical Report

\title{
Effect of Operating Conditions and Fractional Condensation on Pyrolytic Products
}

\author{
Norizan Ali*1, Yoshimitsu UEMURA*1, Hafizah AHMAD AFIF *1, Noridah B OSMAN*1, \\ Wissam N. OMAR*1, Bawadi ABDULLAH *2, and Toshio TSUTSUI*3 \\ (Received May 21, 2013)
}

\begin{abstract}
The effects of biomass type, size, and pyrolysis temperature on pyrolytic products distribution have been investigated. Hence, reaction temperatures $\left(400,450,500\right.$, and $550{ }^{\circ} \mathrm{C}$ ) and biomass feedstock sizes (0.15-0.5, 0.5-1.0, and 1.0-2.0 mm) were applied. Decomposition of palm kernel shell and mesocarp fiber was performed in a fluidized bed pyrolyzer with nitrogen gas flow rate of $25 \mathrm{~L}(\mathrm{NTP}) / \mathrm{min}$. The maximum bio-oil yield (39.6 \%) was gained from PKS of $0.15-0.5 \mathrm{~mm}$ at $500{ }^{\circ} \mathrm{C}$. Many evidence showed that small particle size produced the most noticeable amount of bio-oil production. The fluidized bed pyrolysis reactor used possesses six successive condensers operated at three temperatures. Thus, six fractions of bio-oil samples were obtained from these six condensers. The properties of each bio-oil sample were determined including calorific value, elements, water and ash contents, and major compounds in the bio-oils. The compositions of water and major compounds in the fractional liquids of these six successive condensers were also reported.
\end{abstract}

\section{Key Words}

Fast pyrolysis, Fluidized bed reactor, Mesocarp fiber, Palm kernel shell

\section{Introduction}

In Malaysia, utilization of biomass specifically from the agricultural sector has drawn great attention for the last two decades due to its abundant amount and carbon neutrality. Malaysian Palm Oil Council (MPOC) reported that Malaysia contributes $44 \%$ palm oil of world exports resulting in million tonnes of waste generated from this industry every year ${ }^{1)}$. Moreover, the wastes such as palm kernel shell (PKS) and mesocarp fiber have economic values and environmental friendliness for energy production. Typically, fresh fruit bunches can generate about 5-7 \% PKS and $13 \%$ mesocarp fiber ${ }^{2)}$. From July to December in 2011, about 93 million tonnes of fresh fruit bunches were processed $^{3)}$. As a result, it was estimated that 4-7 million tonnes of PKS and around 12 million tonnes of mesocarp fiber were generated and these numbers will inevitably

* 1 Centre for Biofuel and Biochemical Research (CBBR), Universiti Teknologi PETRONAS 31750 Tronoh, Perak, Malaysia

* 2 Department of Chemical Engineering, Universiti Teknologi PETRONAS 31750 Tronoh, Perak, Malaysia

* 3 Department of Chemical Engineering, Kagoshima University 1-21-40 Korimoto, Kagoshima 890-0065, Japan continue to grow.

Pyrolysis is a promising technology to decompose biomass into three types of products; bio-oil, char, and gas for bio-fuel and biochemical production. The desired product from pyrolysis is bio-oil, also known as pyrolytic oil or bio crude. Bio-oil is more convenient to use, store, and transport. One of the recent pyrolysis technologies is the fluidized bed reactor. Many studies have investigated the effect of different parameters on bio-oil yield and its properties by using fluidized bed reactor ${ }^{4) ~ 8)}$. Their studies presented the fluidized bed pyrolysis systems with one unit condens-

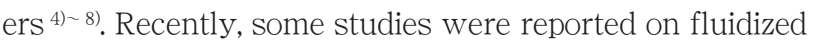
bed pyrolysis system with multiple condensers (two or three condensers) ${ }^{\text {9) 12) }}$ to have more bio-oil fractions as well as to increase its yield. This is in line with the idea that the production and the quality of bio-oil in the pyrolysis system could also be enhanced by an effective condensation process. On top of that, information on characteristics of the fractional bio-oils is still much limited. As a result, most studies have reported characteristics of these fractional biooils as a whole bio-oil.

In this study, PKS and mesocarp fiber were utilized to produce bio-oil through pyrolysis process. Pyrolysis of these 
biomass residues was carried out in a fluidized bed pyrolysis system which consists of one fluidized bed reactor, two cyclones, and six successive condensers at downstream section to separate char and to trap bio-oil, respectively. The objective was to investigate the effects of biomass feedstock type, size, and temperature on the pyrolysis products distribution. The distributions of water in the six fractions of bio-oil from the six successive condensers were determined at three temperatures. The bio-oils were characterized and their ash content, calorific value, element content, and the concentration of major compounds were identified.

\section{Experimental}

\subsection{Biomass samples}

Samples of PKS and mesocarp fiber were obtained from a palm oil mill in Perak, Malaysia. The received PKS was in the form of irregular half-bowl shape. PKS and mesocarp fiber were dried in a drying oven (Memmert, 100800 model) at $105{ }^{\circ} \mathrm{C}$ for $24 \mathrm{~h}$, grinded using an analytical mill (Fritsch, Pulverisette model), then sieved to segregate their size to $0.15-0.5,0.5-1.0$, and 1.0-2.0 mm respectively. All samples were kept in airtight containers to prevent from moisture gain and redried for overnight before every experiment to remove any moisture gain during the storage. The main characteristics of the samples are tabulated in Table 1.

All results presented are based on dried basis and each testing was replicated three times in order to obtain reliable data. For the proximate analysis, ash, moisture, and volatile matter contents of the biomass feedstock were determined by referring to ASTM E 1755-95, E 871-82, and EM 15148, respectively. Fixed carbon content was determined by the difference. The elemental analysis was carried out using a Perkin Elmer 2400 CHN analyzer. The hydrogen content obtained from the instrument was the

Table 1 Biomass feedstocks characteristics

\begin{tabular}{lcccc}
\hline Biomass & PKS & PKS & PKS & $\begin{array}{c}\text { Mesocarp } \\
\text { Fiber }\end{array}$ \\
\hline Size $[\mathrm{mm}]$ & $0.15-0.5$ & $0.5-1.0$ & $1.0-2.0$ & $0.15-0.5$ \\
\hline Proximate [wt\%] & & & & \\
Moisture & 4.27 & 4.54 & 3.65 & 4.41 \\
Volatile matter & 73.81 & 75.35 & 73.84 & 85.93 \\
Fixed carbon & 19.70 & 18.62 & 20.66 & 3.50 \\
Ash & 2.22 & 1.49 & 1.85 & 6.16 \\
\hline Elemental [wt\%] & & & & \\
C & 48.94 & 50.43 & 50.55 & 44.24 \\
H & 5.41 & 5.82 & 5.76 & 6.73 \\
N & 0.43 & 0.29 & 0.38 & 1.10 \\
\hline HHV [MJ/kg] & 18.95 & 19.39 & 19.00 & 18.79 \\
\hline
\end{tabular}

hydrogen content of the biomass feedstock and moisture in the biomass feedstock. Therefore, to estimate the actual hydrogen content of the biomass feedstock, hydrogen content from the moisture must be subtracted from the hydrogen content given by the instrument as described in Equation 1;

$$
H_{\text {biomass } W t \%}=H_{\text {chn } W t \%}-\text { Moisture } w t \% \times \frac{2 A W_{\mathrm{H}}}{M W_{\mathrm{H} 20}}
$$

where $\mathrm{AW}_{\mathrm{H}}$ and $\mathrm{MW}_{\mathrm{H} 2 \mathrm{O}}$ are the atomic weight of hydrogen and molecular weight of water, respectively. The calorific value was measured using a bomb calorimeter (IKA Werke, C5003). The obtained calorific value is the high heating value (HHV), which includes the latent heat of the vapor released from the sample.

\subsection{Fluidized bed pyrolyzer setup}

A schematic diagram of the bench scale fluidized bed pyrolyzer is shown in Fig. 1. The pyrolysis experiments have been carried out in a bench scale fluidized bed pyrolyzer. The system consisted of a feeding system, a fluidized bed reactor, a char-separation system, and a fractional condensation system. The feeding system was equipped with a hopper and an adjustable-speed screw feeder to feed the biomass feedstock to the reactor consistently. The feedstock moved directly into the fluidized bed containing bed material of silica sands with a diameter of $0.2 \mathrm{~mm}$. The fluidized bed reactor was made of Inconel 625 and equipped with four electric jacket heaters with PID (proportional-integral-derivative) controllers. The inner diameter and the length of the fluidized bed reactor were $108 \mathrm{~mm}$ and 763 $\mathrm{mm}$, respectively. The char-separation system consisted of two cyclones to collect fine char particles. The fractional condensation system consisted of three stages. The first and the second stage condensers were made of stainless steel and operated at $27{ }^{\circ} \mathrm{C}$ and $6{ }^{\circ} \mathrm{C}$, respectively, whereas the third stage consisted of 4 glass condensers which were half submerged under ethylene glycol at $-10{ }^{\circ} \mathrm{C}$ in a cool bath. This fractional condensation system condensed pyrolysis vapors to six fractions with the order of the saturated vapor pressure.

The pyrolysis process was operated at atmospheric pressure. The reactor temperature was raised to the desired temperature. Nitrogen $\left(\mathrm{N}_{2}\right)$ gas was injected into the fluidized bed reactor at $25 \mathrm{~L}(\mathrm{NTP}) /$ min during the temperature elevation and pyrolysis process. The $\mathrm{N}_{2}$ gas was preheated at $500{ }^{\circ} \mathrm{C}$ before entering the reactor. $500 \mathrm{~g}$ of biomass feedstock was continuously fed at $1.5 \mathrm{~kg} / \mathrm{h}$ when the temperature of the fluidized bed reactor reached the desired level.

After the experiment, bio-oil samples were collected 


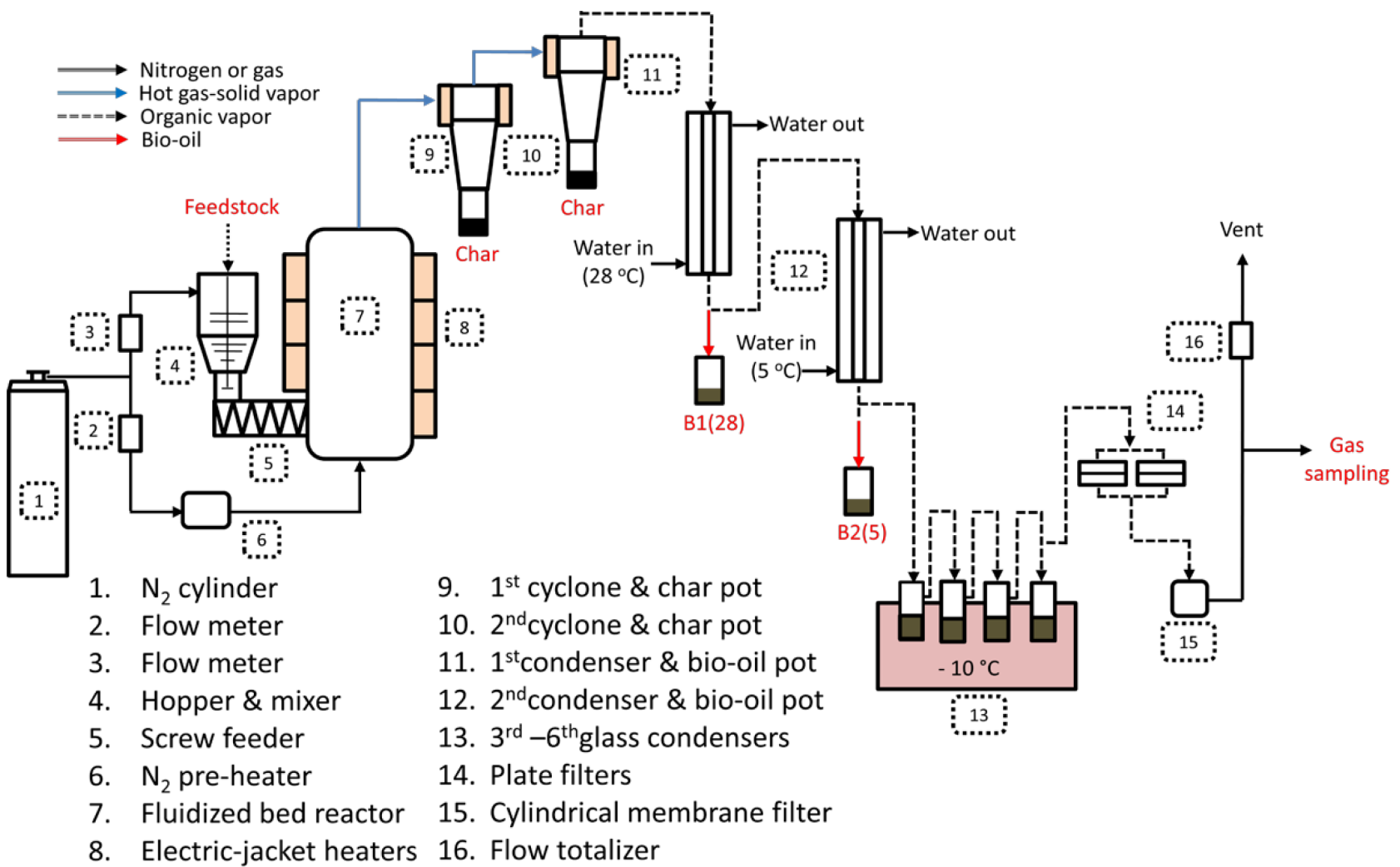

Fig. 1 Fluidized bed pyrolysis system

from the six successive condensers while char was recovered from the fluidized bed and the two cyclones. All the samples were weighed to determine their yield while gas yield was calculated by difference, using the bio-oil and the char yields. In addition, some bio-oil was recovered from other parts of the fractional condensation system such as tubing, teflon tube, and filters. The weights of the recovered bio-oil were determined by weighing these parts before and after the experiment.

\subsection{Pyrolysis conditions}

Experimental conditions for pyrolysis process are as follows. Three ranges of particle size investigated were 0.15 0.5, 0.5-1.0, and 1.0-2.0 mm. All experiments were performed at temperature of $450{ }^{\circ} \mathrm{C}$.

The best particle size $(0.15-0.5 \mathrm{~mm})$ which produced the highest bio-oil yield was utilized to investigate the optimum temperature, in the range of $400{ }^{\circ} \mathrm{C}$ to $550{ }^{\circ} \mathrm{C}$.

Additional experiment was performed on different type of biomass, mesocarp fiber with the best particle size and temperature which were $0.15-0.50 \mathrm{~mm}$ and $500{ }^{\circ} \mathrm{C}$, respectively.

\subsection{Bio-oils characterization}

Elemental composition and calorific value of the bio-oils were determined using a CHN analyzer (PERKIN ELMER,
2400) and a bomb calorimeter (IKA Werke, C5003), respectively, while ash content analysis was referred to ASTM E 1755-95. The water content of bio-oils was analyzed using a volumetric Karl Fischer Titrator (Mittler Toledo, V30). Titration reagent and titration solvent used for $\mathrm{KF}$ titration were HYDRANAL Composite 5K (Riedel-de Haen) and HYDRANAL Working Medium K (Riedel-de Haen), respectively. Chemical analysis was performed using a GC/FID (Shimadzu, GC-2014) with a BPX5 $(30 \mathrm{~m} \times 0.25 \mathrm{~mm} \times 0.25 \mu \mathrm{m})$ capillary column. The oven temperature was set at $35{ }^{\circ} \mathrm{C}$, held for $2 \mathrm{~min}$. Then, with the heating rate of $20{ }^{\circ} \mathrm{C} / \mathrm{min}$, the temperature was raised to $250{ }^{\circ} \mathrm{C}$ and held for $20 \mathrm{~min}$. Detector and injector temperatures were set at $280{ }^{\circ} \mathrm{C}$.

\section{Results and Discussion}

\subsection{Effect of particle size on the products yield}

Fig. 2 shows the yield of bio-oil, char, and gas at $450{ }^{\circ} \mathrm{C}$ with three different sizes, 0.15-0.5, 0.5-1.0, and 1.0-2.0 mm. The yield is described as the percentage of mass of a product relative to the total mass of a feedstock. The bio-oil yield clearly decreased with an increase in particle size. The highest bio-oil yield of $27.4 \%$ was obtained with the smallest particle size (0.15-0.5 $\mathrm{mm})$ due to better heating rate ${ }^{9) 10}$ in comparison with $21.7 \%$ for the biggest particle size (1.0$2.0 \mathrm{~mm})$. At $450{ }^{\circ} \mathrm{C}$ with the same power input for the heating process, the smallest particle size feedstock was heated 


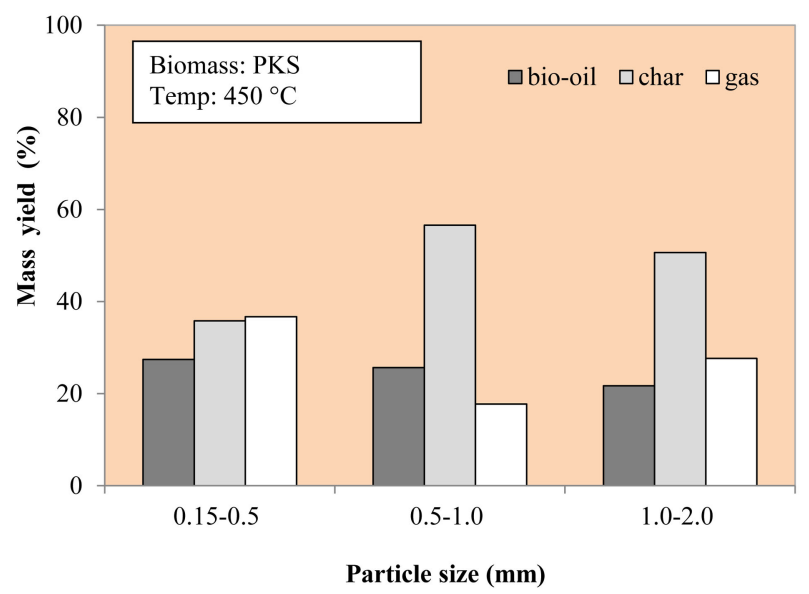

Fig. 2 Effect of particle size on the products yield

rapidly to release volatile matter and formed char with the actual average particle heating rates. Thus, the bio-oil yield of small particle size was higher compared to big particle size. The char yield increased with an increase in particle size due to the low heating rate of biomass decomposition process, from $35.8 \%$ to $56.6 \%$.

It is noticeable that char yield of middle size $(0.5-1.0 \mathrm{~mm})$ was slightly higher than the biggest size (1.0-2.0 mm), with the increase by $6.0 \%$. This observation is in agreement with the finding reported by Seon et al. whereby biomass with smaller size (0.425-0.85 mm) yielded a slightly higher char by $8.0 \%$ compared to the bigger size $(0.85-1.0 \mathrm{~mm})^{10)}$.

For gas product, the highest gas yield of $35.8 \%$ was also obtained with smallest size $(0.15-0.5 \mathrm{~mm})$. The trend is consistent with a previous study ${ }^{9}$. This can be attributed to the conversion of volatile to gas due to the overheating of the smaller size particles ${ }^{9}$.

\subsection{Effect of reaction temperature on the products yield}

Fig. 3 shows the distribution of pyrolysis products as a function of the reaction temperature. The maximum biooil yield was obtained at $500{ }^{\circ} \mathrm{C}$. As the temperature el-

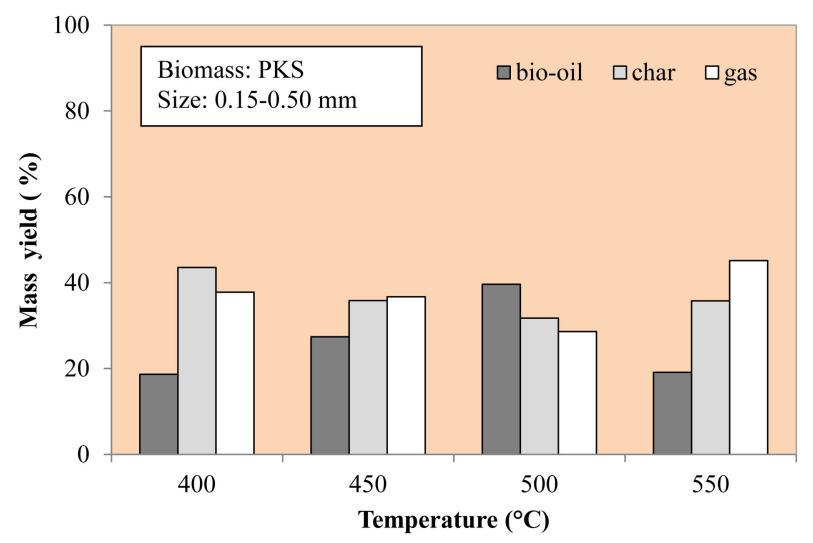

Fig. 3 Effect of temperature on the products yield evated from $400{ }^{\circ} \mathrm{C}$ to $500{ }^{\circ} \mathrm{C}$, the bio-oil yield increased from $18.7 \%$ to $39.6 \%$, whereas the char and gas yields declined from $43.5 \%$ to $31.8 \%$ and from $37.8 \%$ to $28.6 \%$, respectively. This phenomenon probably happened when biomass feedstock is fed into the fluidized bed reactor, the biomass feedstock is rapidly heated to produce volatile and to form char. This is called the primary reaction. The char particles remain in the bed, and are pyrolysed until they turn out to be sufficiently small and light, at which they are entrained by the fluidization gas. The volatiles are converted into char, or catalytically converted into gases by the chars and homogeneously in the bed. This is called the secondary reaction. Although both the primary and secondary reactions become faster as the pyrolysis temperature increases, the primary reaction may be predominant at lower to intermediate temperatures. The bio-oil yield therefore increases in this temperature range of $400{ }^{\circ} \mathrm{C}$ to $500{ }^{\circ} \mathrm{C}$. Even though temperature of the top zone of the reactor was always higher than temperature of the bottom zone, but the temperature of the top zone went up only around $500{ }^{\circ} \mathrm{C}$.

At higher temperature, the secondary reaction overtakes the primary reaction. The bio-oil therefore starts to decrease at the temperature ranges of $500{ }^{\circ} \mathrm{C}$ to $550{ }^{\circ} \mathrm{C}$. In fact, at $550{ }^{\circ} \mathrm{C}$, temperature of the top zone went up to around $640{ }^{\circ} \mathrm{C}$ and hence the volatiles underwent intensive gasification reaction and led to increase the gas yield with $45.1 \%$ and to decrease the bio-oil yield to $19.1 \%$. This trend is consistent with the previous studies ${ }^{10) 14) ~ 16)}$.

\subsection{Effect of biomass type on the products yield}

Fig. 4 shows the distribution of pyrolysis products produced from PKS and mesocarp fiber at the best temperature $\left(500{ }^{\circ} \mathrm{C}\right)$. The bio-oil yield of PKS was slightly higher than that of mesocarp fiber, as well as the char production. This could be due to the fixed carbon content of mesocarp fiber which was relatively low with only 3.5 wt\%. In gen-

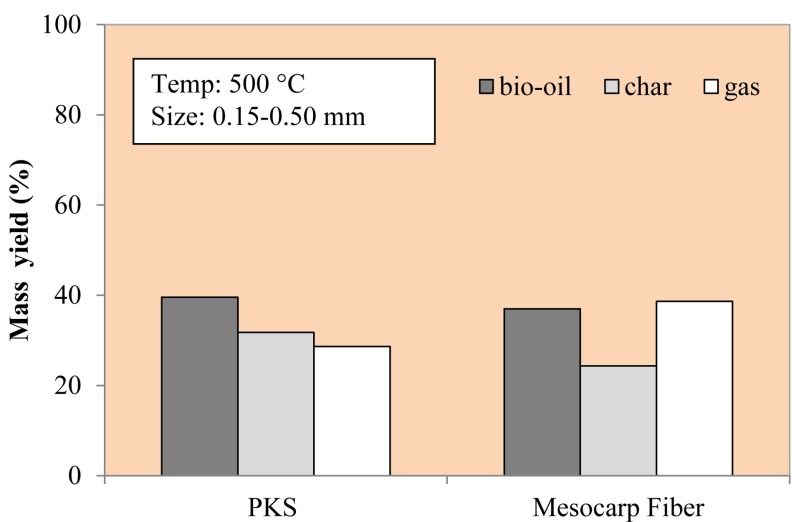

Fig. 4 Effect of biomass type on the products yield 
eral, biomass with high fixed carbon content shows high char yield ${ }^{17)}$. On the other hand, mesocarp fiber produced higher gas yield than PKS with $38.6 \%$ due to the impact of its ash content ( $6.16 \mathrm{wt} \%)$. Ash consists mostly of inorganics and among them, alkaline and alkaline earth metals are known to act as a gasification catalyst for char ${ }^{6}$. Ash is also catalytically active for cracking the volatiles (secondary cracking), which lead to increase the gas formation, causing less yield of bio-oil at the end of the process.

\subsection{Effect of fractional condensation on the distribution of water in bio-oils}

Due to the highest bio-oil yield, bio-oil produced from smallest size of PKS at $500{ }^{\circ} \mathrm{C}$ was selected to be discussed on the effect of fractional condensation. Fig. 5 shows the distribution of the bio-oil and water in the fractional biooils corresponding to the six condensers with three temperatures. Other which mentioned in Fig. 5 is referred to bio-oil recovered from the other parts of the system which were explained earlier. The distribution of bio-oils in each condenser is depending on the temperature of the condensers in which they are condensed.

The results indicated that the bio-oil collected at the first condenser was tarry and extremely viscous with black color. Therefore, the sample was not analyzed using Karl Fischer Titrator. We speculate that the water content in the tar will be low due to the high temperature of the 1st condenser which was at $27{ }^{\circ} \mathrm{C}$. At this temperature, water stayed in the vapor phase and passed to the 2nd condenser 11). Meanwhile, in the 2nd and 3rd condensers, more water vapor was condensed due to the lower temperatures, $5{ }^{\circ} \mathrm{C}$ and $-10{ }^{\circ} \mathrm{C}$, respectively. Hence, bio-oils collected in the 2 nd and 3rd condensers were mainly aqueous and had high water content. Bio-oils collected from the 4th, 5 th and 6 th condensers had less water contents than the bio-oil collected from the 3rd condenser even though their condensation

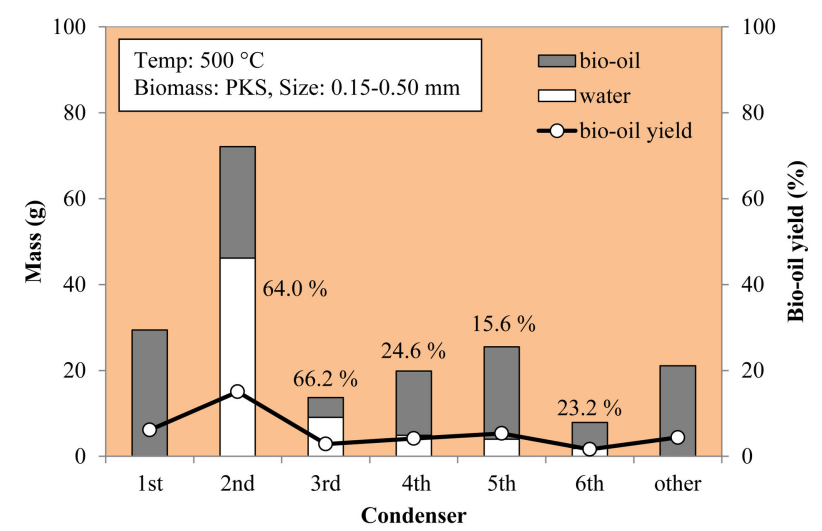

Fig. 5 Effect of fractional condensation on the distribution of bio-oils and water in the bio-oils temperatures were the same. This might be due to a lot of water vapor was already condensed in the 2nd and 3rd condensers before the vapor proceeded to the later condensers.

As shown in Fig. 5, the presence of $46 \mathrm{~g}$ of water in the 2 nd bio-oil led to an increase in the bio-oil yield (15.06 $\%$ ) of the 2nd condenser. On the other hand, bio-oils collected from 3 rd to 6 th condensers have a lower yield ranging from $1.65 \%$ to $5.33 \%$. Even though the bio-oil yield of the later condensers is lower, but by applying this fractional condensation, most of the water could be separated from the bio-oil which have condensed in the 2 nd and $3 \mathrm{rd}$ condensers. Separation of water is crucial as the presence of water in bio-oils could lower the energy content (calorific value) and flame temperature of the bio-oils ${ }^{18)}$.

\subsection{Characteristics of bio-oils}

Table 2 shows some of the important characteristics of the same bio-oils which was discussed in section 3.4. As mentioned earlier, due to high water content, 2nd and 3rd bio-oil could not be analysed for their calorific values using a bomb calorimeter. To overcome this issue, methanol was added to the bio-oils to improve their energy content. The calorific values of the 2 nd and $3 r d$ bio-oils then were determined by subtracting the calorific value of methanol from the calorific value of the mixture, methanol and biooil. As expected, the calorific values of the 2 nd and $3 \mathrm{rd}$ biooils were very low which less than $6 \mathrm{MJ} / \mathrm{kg}$ and just a little lower than reported by Abnisa et al. ${ }^{16)}$. The highest calorific value was obtained by the 1st bio-oil (tar) with $23 \mathrm{MJ} /$ $\mathrm{kg}$ while the calorific values of 4 th to 6 th bio-oils were ranging from $16 \mathrm{MJ} / \mathrm{kg}$ to $19 \mathrm{MJ} / \mathrm{kg}$. Moreover, the calorific value of bio-oil primarily depends on the carbon and oxygen contents. High carbon and less oxygen contents in bio-oil lead to a higher calorific value of the bio-oil. Carbon and oxygen contents of bio-oils collected from the 4th to 6th condensers were comparable with the results reported by literatures ${ }^{1019)}$. Ash content was found high in the 1st bio-oil (tar) with 3.78 wt\% whereas in the rest bio-oils ash content was found to be zero substantially. The presence of ash in bio-oil can cause erosion, corrosion, and kicking problems in the engines and the valves ${ }^{18)}$. Furthermore, deterioration also could happen if the ash content is higher than $0.1 \mathrm{wt} \%{ }^{18)}$.

Bio-oil is a very complex mixture of water, carboxylic acids, phenols, aldehydes, ketones, alcohols, esters, anyhydrosugars, and so forth ${ }^{20}$. The major compounds in 2nd to 6th bio-oils were particularly acetic acid and phenol. Most of the literatures reported that acetic acid and phenol are the compounds with the highest concentration. 
Table 2 Bio-oil characteristics

\begin{tabular}{lcccccc}
\hline & \multicolumn{5}{c}{ PKS $\left(0.15-0.50 \mathrm{~mm}, 500{ }^{\circ} \mathrm{C}\right)$} \\
\cline { 2 - 7 } Bio-oil/condenser & 1st & 2nd & 3rd & 4 th & 5 th & 6th \\
\hline Elemental [wt\%] & 46.0 & 17.1 & 17.3 & 43.5 & 50.2 & 46.6 \\
$\mathrm{C}$ & 6.87 & 9.25 & 9.30 & 5.53 & 7.04 & 8.03 \\
$\mathrm{H}$ & 0.38 & 0.08 & 0.00 & 0.07 & 0.15 & 0.21 \\
$\mathrm{~N}$ & 46.7 & 73.5 & 73.4 & 50.9 & 42.6 & 42.2 \\
$\mathrm{O}^{\text {a }}$ & $\mathrm{NA}$ & 64.0 & 66.2 & 24.6 & 15.6 & 23.2 \\
\hline Water [wt\%] & 23.0 & 5.76 & 4.55 & 16.8 & 19.4 & 17.61 \\
\hline HHV [MJ/kg] & 3.78 & 0.00 & 0.00 & 0.00 & 0.00 & 0.00 \\
\hline Ash [wt\%] & & & & & & \\
\hline Quantitative of major compound [wt \%] & NA & 9.26 & 9.69 & 13.9 & 14.6 & 14.4 \\
Acetic acid & NA & 2.07 & 3.40 & 12.3 & 15.0 & 13.9 \\
\hline Phenol & & & & & &
\end{tabular}

a By difference

Typical wood normally produced $0.5 \mathrm{wt} \%$ to $12 \mathrm{wt} \%$ and 0.13 wt\% to $3.8 \mathrm{wt} \%$ of acetic acid and phenol, respectively ${ }^{21)}$ while crops biomass produced acetic acid ranging from $2.0 \%$ to $3.5 \%$ and $1 \%$ of phenol based on relative area from GC/ $\mathrm{MS}^{22)}$. On the other hand, due to high lignin content in PKS, phenol concentration was higher compared to acetic acid in general. Normally phenol concentration ranges from 13 $\%$ to $22 \%$, which is higher than acetic acid concentration of around $5 \%{ }^{1016)}$. However, in our study, acetic acid concentration was found higher than phenol concentration in all six bio-oil fractions in general. Even though phenol concentration was lower than acetic acid concentration in all condensers, it still found high in the 4th to 6th condensers. From this observation, the fractional condensers are good for preliminary separation of water and phenol.

\section{Conclusion}

Pyrolysis of palm kernel shell (PKS) and mesocarp fiber was performed and investigated. The maximum biooil yield $39.6 \%$ was achieved at temperature of $500{ }^{\circ} \mathrm{C}$ for PKS. The particle sizes did show a persistent effect on the bio-oil yield. The bio-oil yield is depending to the particle size. The smallest particle size $(0.15-0.50 \mathrm{~mm})$ biomass produced the highest bio-oil yield. In term of fractionation of bio-oil, the fractional condensers proved to be successful in separating water with other valuable chemicals. The phenol in the organic phase was segregated which highly found in the organic phase at the later condensers (4th to 6th condensers).

\section{Acknowledgements}

Authors wish to thank the Mitsubishi Corporation Education Trust Fund for the financial support and the Chemical Engineering Department of Universiti Teknologi
PETRONAS for supporting this research.

\section{References}

1) Malaysian Palm Oil Council, http://www.mpoc.org.my/ Malaysian_Palm_Oil_Industry.aspx (Access on 30 November 2012)

2) Okoroigwe, E. C.; Saffron, C. M.: Niger. J. Technol., 31, 329$335(2012)$

3) Malaysian Palm Oil Board: http://bepi.mpob.gov.my/ index.php/statistics/sectoral-status/75-sectoral-status2011/323-ffb-processed-by-mill-2011.html (Access on 30 November 2012)

4) Huiyan, Z:; Rui, X.; Denghui, W.; Guangying, H.; Shanshan, S.; Jubing, Z:; Zhaoping, Z.: Bioresour. Technol., 102, 4258$4264(2011)$

5) Zhongyang, L.; Shurong, W.; Yanfen, L.; Jinsong, Z.; Yueling, G.; Kefa, C.: Biomass. Bioenerg., 26, 455-462(2004)

6) Abdullah, A.; Gerhauser, H.: Fuel, 87, 2606-2613(2008)

7) Asadullah, M.; Rahman, M. A.; Ali, M. M.; Motin, M. A.; Sultan, M. B.; Alam, M. R.; Rahman, M. S.: Bioresour. Technol., 99, 44-50 (2008)

8) Zheng, J. L.: J. Anal. Appl. Pyrolysis, 83, 205-212(2008)

9) Hyeon, S. H.; Hyun, J. P.; Yong, K. P.; Changkok, R.; Dong, J. S.; Young, W. S.; Jin, H. Y.; Seung, S. K.: Bioresour Technol., 101, S91-S96 (2010)

10) Seon, J. K.; Su, H. J.; Joo, S. K.: Bioresour. Technol., 101, 9294$9300(2010)$

11) Chih, C. C.; Seng, R. W.; Chi, C. L.; Hou, P. W.; Hom, T. L.: Energ. Fuel, 26, 2962-2967(2012)

12) Huiyan, Z.; Rui, X.; He, H.; Gang, X.: Bioresour. Technol., 100, 1428-1434(2009)

13) Jun, S.; Xiao, S. W.; Manuel, G. P.; Daniel, M.; Martin, J. R.; Chun, Z. L.: Fuel, 88, 1810-1817(2009)

14) Jung, S. H.; Kang, B. S.; Kim, J. S.: J. Anal. Appl. Pyrolysis, 
82, 240-247(2008)

15) Jung, S. H.; Kim, S. J.; Kim, J. S.: Bioresour. Technol., 114, 670-676(2012)

16) Abnisa, F.; Daud, W. M. A. W.; Husin, W. N. W.; Sahu, J. N.: Biomass. Bioenerg., 35, 1863-1872(2011)

17) Mohammad, I. J.; Mohammad, G. R.; Ashfaque, A. C.; Nanjappa, A.: Energ., 5, 4952-5001 (2012)

18) Zhang, Q.; Chang, J.; Wang, T.; Xu, Y.: Energ. Convers. Manage., 48, 87-92 (2007)
19) Mohammad, N. I.; Ramlan, Z.; Farid, N., A.: Renew. Energ., 17, 73-84(1999)

20) Xue, S. Z.; Guang, X. Y.; Hong, J.; Wu, J. L.; Hong, S. D.: Sci. Rep., 3, 1120 (2013)

21) Diebold, J. P. A.: Fast Pyrolysis of Biomass: A handbook, (CPL Scientific Publishing: Newbury, UK), p. 135-163 (2003)

22) Mullen, C. A.; Boateng, A. A.: Energ. Fuels, 22, 2104-2109 (2008) 